\title{
Antioxidant Balance and Regulation in Tomato Genotypes of Different Color
}

\author{
Cristián Vela-Hinojosa \\ Biotechnology PhD Program, Universidad Autónoma Metropolitana Iztapalapa, Mexico City, Mexico
}

Héctor B. Escalona-Buendía

Departamento de Biotecnología, Universidad Autónoma Metropolitana Iztapalapa, Mexico City, Mexico

\author{
José A. Mendoza-Espinoza \\ Colegio de Ciencias y Humanidades, Universidad Autónoma de la Ciudad de México, Mexico City, \\ Mexico
}

\author{
Juan M. Villa-Hernández \\ Departamento de Ciencias de la Salud, Universidad Autónoma Metropolitana Iztapalapa, Mexico \\ City, Mexico \\ Ricardo Lobato-Ortíz \\ Departamento de Recursos Genéticos y Productividad, Colegio de Postgraduados, Mexico, Mexico
}

Juan E. Rodríguez-Pérez

Departamento de Fitotecnia, Universidad Autónoma Chapingo, Mexico, Mexico

Laura J. Pérez-Flores ${ }^{1}$

Departamento de Ciencias de la Salud, Universidad Autónoma Metropolitana Iztapalapa, Mexico

City, Mexico

\begin{abstract}
AdDitional INDEX wORDS. anthocyanins, polyphenols, flavonoids, PSY
Abstract. Antioxidants, antioxidant capacity, and the expression of isoprenoid metabolism-related genes and two pigmentation-related transcription factors were studied in four native and four hybrid tomato (Solanum lycopersicum) genotypes with different-colored fruit. Red fruit genotypes were associated with greater lycopene, $\beta$-carotene, lipophilic antioxidant capacity, and greater chromoplast-specific lycopene $\beta$-cyclase $(C Y C$ - $B)$ transcript levels. Orange fruit genotypes had greater concentrations of tocopherols and greater transcript levels of homogentisate phytyl transferase (VTE-2), 1-deoxy-D-xylulose phosphate synthase (DXS), and 4-hydroxyphenylpyruvate dioxygenase (HPPD). The yellow fruit genotype was greater in total polyphenol and hydrophilic antioxidant capacity with greater expression of geranylgeranyl reductase $(G G D R)$, phytol kinase (VTE-5), phytoene synthase (PSY) 2, lycopene $\beta$-cyclase $(L C Y-B), S I N A C 1$, and SINAC4. Greater levels of individual antioxidants were associated with specific coloration of tomato fruit. Moreover, the negative correlations between the expression of PSY1 and VTE5, and between lycopene and chlorophyll, suggest a balance between carotenoids, tocopherols, and chlorophylls. The results of this study support either the direct commercialization of tomatoes with different color fruit or use of their genotypes in breeding programs to increase antioxidant levels among existing cultivars.
\end{abstract}

Tomato fruit are an excellent source of antioxidants and contribute significantly to human health because of their antiinflammatory, antiallergenic, and antithrombotic properties. Carotenoids and tocopherols are among the major lipophilic antioxidants present in tomatoes, whereas hydrophilic antioxidants include vitamin $\mathrm{C}$ and polyphenols (Viuda-Martos et al., 2014). Polyphenols are powerful antioxidants that have been reported to interfere with the initiation, promotion, and progression of cancer and can be divided into different groups according to their structure. The main tomato polyphenols are hydroxycinnamic acids, flavanones, flavonols, and anthocyanins

Received for publication 22 Aug. 2018. Accepted for publication 31 Oct. 2018 We thank CONACYT (Consejo Nacional de Ciencia y Tecnología; scholarship 265752) and UAM (Universidad Autónoma Metropolitana) for its financial support. ${ }^{1}$ Corresponding author. E-mail: ljpf@xanum.uam.mx or laujperez@yahoo.com. $\mathrm{mx}$.

J. Amer. Soc. Hort. ScI. 144(1):45-54. 2019.
(Martí et al., 2016). Tomato fruit has been widely used as a model for the study of fleshy fruit ripening because of its unique characteristics, such as the presence of well-characterized ripening mutants, reduced plant size, a well-characterized genome, and a short life cycle (Liu et al., 2015).

The red pigmentation of the ripe fruit is one of the most recognizable features of the commercial tomato. The change from green to red occurs due to the degradation of chlorophyll and the accumulation of carotenoids. The carotenoids that accumulate in commercial tomato fruit are lycopene $(\approx 90 \%)$, $\beta$-carotene (5\% to $10 \%)$ and lutein $(1 \%$ to $5 \%)$, with only trace concentrations of other compounds (Stahl and Sies, 2003).

In recent years, the biosynthetic pathways of carotenoid, tocopherol, and chlorophyll have been studied because of their importance in understanding the regulatory cross-talk that contributes to the nutritional quality of tomato fruit (Almeida et al., 2014; Quadrana et al., 2013). Carotenoids, tocopherols, 
and chlorophylls are isoprenoid-derived compounds that are synthesized through the 2-C-methyl-D-erythritol-4-phosphate pathway with geranylgeranyl pyrophosphate as a common precursor (Almeida et al., 2014). Chlorophyll metabolism is closely linked to carotenoid and tocopherol biosynthesis, which are the major lipid-soluble antioxidants (Lira et al., 2016). In the metabolic pathway of carotenoid biosynthesis, the enzyme PSY catalyzes the condensation of 2-geranylgeranyl pyrophosphate molecules to form phytoene, the basic skeleton for all carotenoids and an immediate precursor of lycopene (Liu et al., 2015).

Tomatoes have two genes encoding PSY: PSY1 accumulates in chromoplasts, and PSY2 is associated with chloroplasts. The cyclization of lycopene for the formation of the $\beta$-carotene pigment is carried out by two lycopene $\beta$-cyclase enzymes: LCY-B, found in chloroplasts, and CYC-B, found in chromoplasts, which is associated with $\beta$-carotene production during fruit ripening (Klee and Giovannoni, 2011). In this process, the LCY-B and CYC-B also participate in the conversion of lycopene to $\alpha$-carotene, a precursor of the yellow pigment lutein (Guo et al., 2012).

Tocopherol biosynthesis requires the condensation of phytyldiphosphate and homogentisate, derived from the 2-C-methyl-Derythritol-4-phosphate and shikimate pathways, respectively. The first step of the tocopherol pathway is catalyzed by HPPD involving the reduction of 4-hydroxyphenylpyruvate to homogentisate, which is further decarboxylated and then condensed with a prenyl donor by the prenyltransferase, VTE-2. The prenyl donor for tocopherol biosynthesis, phytyl diphosphate, also can be synthesized from phytol recycling after chlorophyll degradation by VTE-5 (Quadrana et al., 2013). Therefore, it is considered that tomato fruit of different colors are an interesting model for the study of the isoprenoid-metabolic cross-talk of tocopherol, chlorophyll, and carotenoid pathways. NAC (NAM/ ATAF1/2/CUC2) genes constitute one of the largest families of plant-specific transcription factors and influence a diverse set of developmental processes. Although $N A C$ genes are involved in stress responses, SINAC-1 (S. lycopersicum NAC-1) and SINAC-4 (S. lycopersicum NAC-4) have been associated with fruit development and carotenoid accumulation (Zhu et al., 2014).

Mexico is a center of diversification and domestication of tomato and thus offers a wide range of native genotypes with fruit of different colors, shapes, and sizes. These genotypes could be integrated into breeding programs aiming to increase the nutraceutical properties of commercial cultivars and recover antioxidant compounds that have been lost through the selection process (Rodríguez et al., 2013). The aim of this study was to evaluate the variation in carotenoid and tocopherol content among selected hybrid and native tomato lines. In addition, the expression of isoprenoid metabolism-related genes and two pigmentation-related transcription factors were determined, as well as assays for antioxidant capacity of the lipophilic and hydrophilic fractions, total polyphenols, flavonoids, anthocyanins, vitamin $\mathrm{C}$, and chlorophylls.

\section{Materials and Methods}

\section{Plant material and collection}

Eight tomato genotypes with different-colored fruit were used for this study (Fig. 1). Four native tomato lines, including 15014 [red $\left(\mathrm{R}_{\mathrm{N}}\right)$ ], 15006-A [orange $\left(\mathrm{O}_{\mathrm{N}}\right)$ ], 15011 [yellow

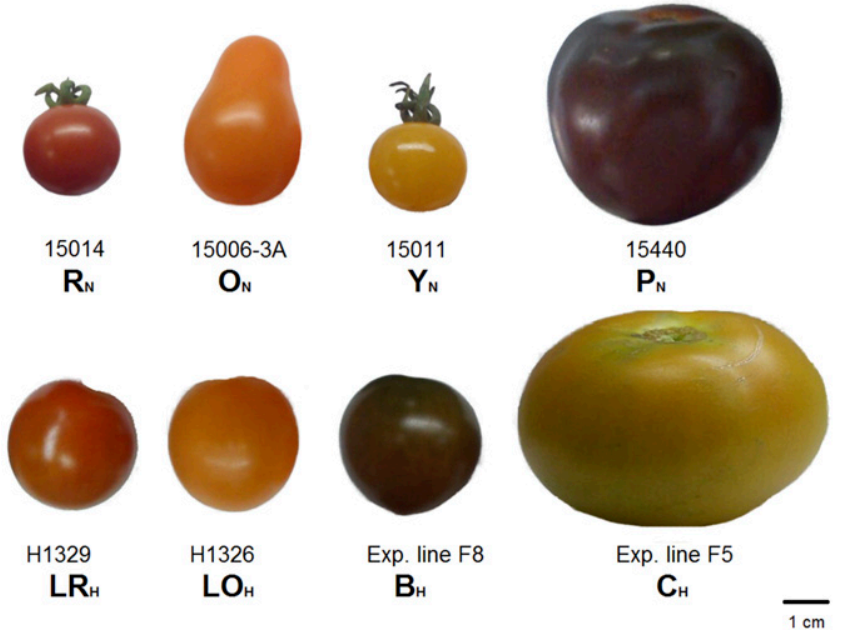

Fig. 1. Studied tomato genotypes and germplasm accession codes. Native genotypes $( \pm \mathrm{SE})$ : red $\left[\mathrm{R}_{\mathrm{N}}\right.$ (accession code 15014 , hue $\left.\left.44.71 \pm 0.94\right)\right]$, orange $\left[\mathrm{O}_{\mathrm{N}}(\right.$ accession code $15006-3 \mathrm{~A}$, hue $\left.70.3 \pm 2.2)\right]$, yellow [ $\mathrm{Y}_{\mathrm{N}}$ (accession code 15011 , hue $81.9 \pm 2.3)]$, purple $\left[\mathrm{P}_{\mathrm{N}}(\right.$ accession code 15440 , hue $\left.56.4 \pm 1.2)\right]$. Hybrid experimental lines: light red $\left[\mathrm{LR}_{\mathrm{H}}\right.$ (accession code H1329, hue $45.2 \pm$ 4.6)], light orange $\left[\mathrm{LO}_{\mathrm{H}}\right.$ (accession code $\mathrm{H} 1326$, hue $\left.\left.70 \pm 3.5\right)\right]$, black $\left[\mathrm{B}_{\mathrm{H}}\right.$ (accession code Exp. line $F 8$, hue $62.4 \pm 1.7$ ) $]$, chartreuse $\left[\mathrm{C}_{\mathrm{H}}\right.$ (accession code Exp, line F5, hue $2.3 \pm 1.5)]$.

$\left(\mathrm{Y}_{\mathrm{N}}\right)$ ], and 15440 [purple $\left(\mathrm{P}_{\mathrm{N}}\right)$ ] were obtained from Colegio de Postgraduados, Mexico. The lines were collected from the following locations: $\mathrm{O}_{\mathrm{N}}$, San Gabriel Chilac, Puebla, Mexico (lat. $18.32611^{\circ} \mathrm{N}$, long. $97.3485^{\circ} \mathrm{W}$, altitude $1232 \mathrm{~m}$ ); $\mathrm{R}_{\mathrm{N}}$ and $\mathrm{Y}_{\mathrm{N}}$, Xicotepec, Puebla (lat. $20.187^{\circ} \mathrm{N}$, long. $97.966^{\circ} \mathrm{W}$, altitude $1142 \mathrm{~m}$ ) and $\mathrm{P}_{\mathrm{N}}$, Tehuacán, Puebla (lat. $18.429^{\circ} \mathrm{N}$, long. $97.466^{\circ} \mathrm{W}$, altitude $1890 \mathrm{~m}$ ). They were subject to individual selection (pedigree method for three generations) so that they would be homozygous lines. Four tomato hybrid experimental lines, H1329 (light red; $\mathrm{LR}_{\mathrm{H}}$ ), H1326 (light orange; $\mathrm{LO}_{\mathrm{H}}$ ), HA (chartreuse; $\mathrm{C}_{\mathrm{H}}$ ), and $\mathrm{HN}$ (black; $\mathrm{B}_{\mathrm{H}}$ ) were obtained from Universidad Autónoma de Chapingo. All genotypes used in this study were part of the Mexican Network of Plant Genetic Resources (Red Mexicana de Recursos Fitogenéticos).

The studied lines, native and hybrid, were planted in a completely randomized block design with three replications, and each experimental unit comprised 10 plants. Native genotypes and hybrid experimental lines were cultivated simultaneously at 22 to $30{ }^{\circ} \mathrm{C}$, with a relative humidity of $75 \%$ in two greenhouses $2.4 \mathrm{~km}$ apart under the same environmental light conditions. The first greenhouse was located at lat. $19.463327^{\circ} \mathrm{N}$, long. $98.907527{ }^{\circ} \mathrm{W}$, altitude $2295 \mathrm{~m}$ and the second was at lat. $19.486792^{\circ} \mathrm{N}$, long. $98.900117^{\circ} \mathrm{W}$, altitude $2295 \mathrm{~m}$. Plants were grown in volcanic sand substrate and a Steiner nutrient solution (Steiner, 1961) leading to plants with a single stem. Fruit were selected when ripe on the basis of a color chart developed specifically for each genotype according to their maximum color development (Namitha et al., 2011). The fruit were harvested free of mechanical damage, physical defects, pests, and blemishes and transported immediately after harvest to the Autonomous Metropolitan University-Iztapalapa. A total of 81 pieces of fruit (three biological replicates of 27 fruit) of each genotype were washed, and the seeds and placenta were removed. Hue was measured in three pieces of fruit of each replicate in three different sections of the fruit surface with a colorimeter 
(ColorFlex 45/0; Konica Minolta, Tokyo, Japan). The remaining fruit tissues were chopped and then frozen and crushed to a powder in liquid nitrogen.

\section{Extraction of the lipophilic and hydrophilic fractions}

Lipophilic and hydrophilic antioxidants were sequentially extracted with $75 \%(\mathrm{v} / \mathrm{v})$ aqueous methanol and dichloromethane $(1: 1 \mathrm{v} / \mathrm{v})$ and then separated by $50 \mathrm{~mm}$ Tris- $\mathrm{HCl}$ buffer, $\mathrm{pH}$ 7.5. One gram of liquid nitrogen-powdered fruit tissue was used for each extraction. Samples were centrifuged in the dark at $4{ }^{\circ} \mathrm{C}$ for $5 \mathrm{~min}$ at $2599 \mathrm{~g}_{\mathrm{n}}$. Each phase (lipophilic and hydrophilic) was used to assess antioxidant composition and capacity. Data were recorded on a fresh weight basis.

\section{In vitro antioxidant capacity}

Antioxidant capacity was assayed in both hydrophilic and lipophilic extracts with three techniques: the 2,2-diphenyl-1picrylhydrazyl (DPPH) method, the 2,2' -azino-bis(3-ethylbenzothiazoline-6-sulfonic acid) (ABTS) assay, and the cupric ion reducing antioxidant capacity (CUPRAC) method. The ABTS assay was performed according to Re et al. (1999) with minor modifications. An ABTS solution was prepared according to Re et al. (1999). This was diluted in 96\% (v/v) ethanol for lipophilic extracts. Absorbance was measured at $734 \mathrm{~nm}$ after $10 \mathrm{~min}$ of reaction.

The DPPH assay was performed using the method described by Brand-Williams et al. (1995). Absorbance was measured at $515 \mathrm{~nm}$ after $15 \mathrm{~min}$ of reaction.

The CUPRAC assay was performed according to Özyürek et al. (2011). In it, $1 \mathrm{~mL}$ of $\mathrm{CuCl}_{2}, 1 \mathrm{~mL}$ of $\mathrm{NH}_{4} \mathrm{AC}$ buffer, $1 \mathrm{~mL}$ of neocuproine, and $1.1 \mathrm{~mL}$ of sample were diluted in water (hydrophilic phase) or 96\% ethanol (lipophilic phase) for a total volume of $4.1 \mathrm{~mL}$. Absorbance was measured at $450 \mathrm{~nm}$.

All the results were acquired by interpolating absorbance on a calibration curve obtained with Trolox and recorded on a fresh weight as micromoles Trolox equivalents (TE) per gram fresh weight.

\section{Hydrophilic antioxidant assays}

Vitamin C (ASCORBIC ACID). Five grams of powder of each sample was homogenized in the dark with a hand blender (2614; Oster, Boca Raton, FL), filtered through gauze, and centrifuged for $5 \mathrm{~min}$ at $2599 \mathrm{~g}_{\mathrm{n}}$ at $4{ }^{\circ} \mathrm{C}$. The amount of ascorbic acid was determined by isocratic elution with highperformance liquid chromatography (HPLC), as described by Nour et al. (2010). Chromatographic separation was performed with an HPLC system (1260 Series; Agilent Technologies, Santa Clara, CA), using $50 \mathrm{~mm}$ potassium dihydrogen orthophosphate buffer, $\mathrm{pH} 2.8$, as a mobile phase (flow rate of $0.7 \mathrm{~mL} \cdot \mathrm{min}^{-1}$ ), a $250 \times 4.6-\mathrm{mm}, 5-\mu \mathrm{m}$ analytical column (Hypersil Gold aQ; Thermo Fisher Scientific, Waltham, MA), and diode array detection at $\lambda=254 \mathrm{~nm}$. The calibration curve was produced using a commercial standard (Sigma-Aldrich, St. Louis, MO).

Total POLYPhenols. Hydrophilic extracts were used to determine total polyphenols. The hydrophilic extract was incubated with Folin-Ciocalteu reagent 1:10 v/v and 7.5\% w/v sodium carbonate for $1 \mathrm{~h}$. The total polyphenol content was determined by spectrophotometry at $765 \mathrm{~nm}$. The results were acquired by interpolating absorbance on a calibration curve obtained with gallic acid. Results were expressed on a fresh weight basis as micrograms of gallic acid equivalents.
Total Flavonoids. Hydrophilic extracts were used to determine total flavonoid content using the method of Chang et al. (2002). The standard curve was obtained with quercetin, and the absorbance was measured at $415 \mathrm{~nm}$. The results were expressed on a fresh weight basis as micrograms of quercetin equivalents.

Total anthocyanins. Hydrophilic extracts were used for the determination of anthocyanin content by the differential $\mathrm{pH}$ method reported by Wrolstad (1993). The absorbance was measured at 520 and $700 \mathrm{~nm}$ at $\mathrm{pH}$ values of 1.0 and 4.5 . The results were expressed as micrograms on a fresh weight basis.

\section{Lipophilic antioxidant assays}

Carotenoids. Carotenoids were extracted from $5 \mathrm{~g}$ of liquid nitrogen-powdered fruit using a mixture of hexane/acetone/ ethanol 50:25:25 [v/v/v (López-Vidal et al., 2016)]. The filtrate was injected into an HPLC (1260 Series; Agilent Technologies) equipped with a $250 \times 4.6-\mathrm{mm}, 5-\mu \mathrm{m}$ column (XTerra C18; Waters Corp., Milford, MA). A multiple wavelength detector $(\lambda=459 \mathrm{~nm})$ was used. The mobile phase consisted of acetonitrile/methanol/dichloromethane (43:43:14 v/v/v), and the flow was $1 \mathrm{~mL} \cdot \mathrm{min}^{-1}$. Commercial standards (SigmaAldrich) were used for the identification and quantification of lycopene, $\beta$-carotene, and lutein. The results were expressed as micrograms on a fresh weight basis.

VitAMin E (TOCOPHeroLs). The lipophilic extract was used to measure tocopherols according to Mène-Saffrané and DellaPenna (2010). The filtrate was injected into an HPLC (1200 Series, Agilent Technologies) equipped with a $250 \times 4-\mathrm{mm}$, 5- $\mu \mathrm{m}$ column (LiChrospher 100 Diol; Merck, Darmstadt, Germany) at $25^{\circ} \mathrm{C}$. A fluorescence detector was used with an excitation and emission wavelength of 296 and $340 \mathrm{~nm}$, respectively. The mobile phase consisted of hexane/methyl tert-butyl ether $(90: 10 \mathrm{v} / \mathrm{v})$, and the flow rate was $1 \mathrm{~mL} \cdot \mathrm{min}^{-1}$. For the identification and quantification of $\alpha-, \beta-, \gamma-$, and $\delta$-tocopherols, calibration curves were constructed using commercial-grade HPLC standards (Millipore, Burlington, MA). Results were expressed as micrograms on a fresh weight basis.

\section{Chlorophyll assay}

The extraction and assay of chlorophylls A and B used the spectrophotometric method described by Costache et al. (2012). One gram of liquid nitrogen-powdered fruit was mixed with a $90 \% \mathrm{v} / \mathrm{v}$ methanol aqueous solution. The measurements were carried out at wavelengths of 666 and $653 \mathrm{~nm}$.

\section{Expression of the genes encoding vitamin $\mathbf{E}$ and carotenoid biosynthetic enzymes}

A total of 11 genes of the pathway of carotenoids, tocopherols, and chlorophylls were selected for this study according to their relevance as regulators. RNA isolation was performed according to the technique reported by Chang et al. (1993). Six grams of fruit was crushed to a powder in liquid nitrogen. The purity and concentration of the RNA were determined by spectrophotometry (absorbance 260/280 nm), and the integrity was verified by $1 \% \mathrm{w} / \mathrm{v}$ agarose gel electrophoresis stained with ethidium bromide. Nine regulatory genes of the pathway of carotenoids, tocopherols, and specific oligonucleotides for genes VTE-2, VTE-5, DXS, and HPPD were used as reported by Almeida et al. (2014) (Table 1), whereas the rest of the oligonucleotides were designed using the software Primer3Plus (Untergasser et al., 2007). 
The identity of amplification products was verified before performing reverse transcription quantitative polymerase chain reaction (RT-qPCR). The amplification efficiency was found to be between $95 \%$ and $100 \%$ for all the studied genes. Two micrograms of RNA were treated with $1 \mathrm{U} \cdot \mu \mathrm{L}^{-1}$ DNase I, RNase free (Thermo Fisher Scientific). The transcripts of interest were amplified by RT-qPCR using the Express SYBR GreenER qPCR Supermix kit (Thermo Fisher Scientific). One microliter of RNA treated with DNase was added per tube in a final volume of $10.5 \mu \mathrm{L}$. The $18 \mathrm{~S}$ RNA fragment was used as a reference gene because it showed minimal variability in its expression between genotypes. The following temperature program was used: reverse transcription reaction at $37{ }^{\circ} \mathrm{C}$ for $10 \mathrm{~min}$, initial denaturation at $95^{\circ} \mathrm{C}$ for $3 \mathrm{~min}, 94^{\circ} \mathrm{C}$ for $30 \mathrm{~s}$, annealing temperature of $58^{\circ} \mathrm{C}(P S Y 1, P S Y 2, C Y C-B$, and $L C Y$ $B)$, or $60^{\circ} \mathrm{C}(G G D R, V T E-2, V T E-5$, and $H P P D)$ for $20 \mathrm{~s}$, and an extension temperature of $72{ }^{\circ} \mathrm{C}$ for $30 \mathrm{~s}$. Thirty cycles were required for all genes, except for LCY-B, which required 32 cycles. Relative mRNA expression was calculated by the $2^{-\Delta \Delta \mathrm{Ct}}$ method (Villa-Hernández et al., 2013). A value of 1 was arbitrarily assigned to every replicate of the mRNA expression of the $\mathrm{R}_{\mathrm{N}}$ genotype, and the relative expression of the other genotypes was calculated using this genotype as reference. Three biological replicates were used and every replicate was loaded two times to minimize the error.

\section{Statistical analysis}

Analyses were carried out using analysis of variance with the Tukey test (significance level of 0.05) using Prism (version 7.0; GraphPad Software, San Diego, CA). Principal component analysis (PCA) was performed using Statgraphics Plus for Windows (version 4.0; StatPoint, Warrenton, VA).

\section{Results and Discussion}

\section{In vitro antioxidant capacity}

In all genotypes, a greater antioxidant capacity was found in the hydrophilic extract compared with the lipophilic extract (Table 2). Differences in antioxidant capacity among genotypes showed the same trend across all three determination methods; however, differences in the lipophilic phase were less discriminating when using the DPPH and CUPRAC methods, probably because the detection wavelengths used for these techniques (515 and $450 \mathrm{~nm}$, respectively) were close to the wavelength at

Table 1. Forward and reverse sequences of oligonucleotides for the 11 genes studied and reference gene (18S) (Almeida et al., 2014).

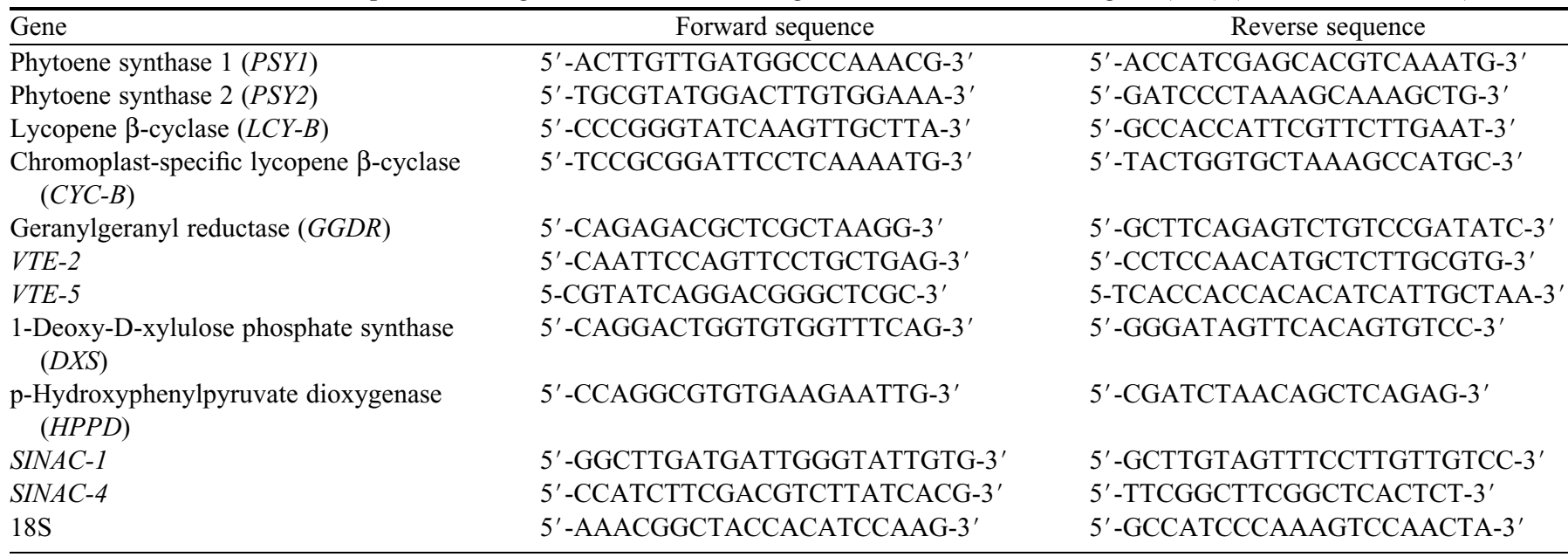

Table 2. Antioxidant capacity of tomato genotypes by 2,2-diphenyl-1-picrylhydrazyl (DPPH) method, cupric ion reducing antioxidant capacity (CUPRAC), and t2,2'-azino-bis(3-ethylbenzothiazoline-6-sulfonic acid (ABTS) methods. Trolox equivalents (TE) values represent the means from three biological replicates of 27 fruit each.

\begin{tabular}{|c|c|c|c|c|c|c|}
\hline \multirow[b]{3}{*}{ Genotype $^{z}$} & \multicolumn{2}{|c|}{$\mathrm{DPPH}$} & \multicolumn{2}{|c|}{ CUPRAC } & \multicolumn{2}{|c|}{ ABTS } \\
\hline & \multicolumn{6}{|c|}{$\mathrm{TE}\left[\mathrm{mean} \pm \mathrm{SE}\left(\mu \mathrm{mol} \cdot \mathrm{g}^{-1}\right)\right]$} \\
\hline & Lipophilic fraction & Hydrophilic fraction & $\begin{array}{l}\text { Lipophilic } \\
\text { fraction }\end{array}$ & $\begin{array}{l}\text { Hydrophilic } \\
\text { fraction }\end{array}$ & Lipophilic fraction & $\begin{array}{l}\text { Hydrophilic } \\
\text { fraction }\end{array}$ \\
\hline $\mathrm{O}_{\mathrm{N}}$ & $0.011 \pm 0.0005 \mathrm{~b}$ & $0.046 \pm 0.0008 \mathrm{~b}$ & $4.42 \pm 0.08 \mathrm{~b}$ & $8.88 \pm 0.30 \mathrm{~b}$ & $0.85 \pm 0.01 \mathrm{~d}$ & $8.02 \pm 0.11 b$ \\
\hline $\mathrm{Y}_{\mathrm{N}}$ & $0.008 \pm 0.0002 \mathrm{~d}$ & $0.054 \pm 0.0017 \mathrm{a}$ & $3.51 \pm 0.10 \mathrm{~d}$ & $12.9 \pm 0.36 \mathrm{a}$ & $0.50 \pm 0.06 \mathrm{e}$ & $11.08 \pm 0.22 \mathrm{a}$ \\
\hline $\mathrm{P}_{\mathrm{N}}$ & $0.009 \pm 0.0002 \mathrm{c}$ & $0.028 \pm 0.0005 \mathrm{~d}$ & $3.78 \pm 0.25 \mathrm{c}$ & $5.61 \pm 0.34 \mathrm{~d}$ & $0.51 \pm 0.02 \mathrm{e}$ & $3.72 \pm 0.10 \mathrm{~d}$ \\
\hline $\mathrm{LO}_{\mathrm{H}}$ & $0.011 \pm 0.0002 \mathrm{~b}$ & $0.032 \pm 0.0006 \mathrm{~d}$ & $4.36 \pm 0.02 b$ & $7.28 \pm 0.66 \mathrm{c}$ & $0.84 \pm 0.02 \mathrm{~d}$ & $7.15 \pm 0.04 \mathrm{c}$ \\
\hline $\mathrm{C}_{\mathrm{H}}$ & $0.005 \pm 0.0004 \mathrm{e}$ & $0.012 \pm 0.0006 \mathrm{e}$ & $3.02 \pm 0.35 \mathrm{~d}$ & $3.29 \pm 0.43 \mathrm{e}$ & $0.40 \pm 0.01 \mathrm{e}$ & $1.86 \pm 0.04 \mathrm{e}$ \\
\hline $\mathrm{B}_{\mathrm{H}}$ & $0.010 \pm 0.0003 \mathrm{~b}$ & $0.040 \pm 0.0003 \mathrm{c}$ & $4.56 \pm 0.25 \mathrm{~b}$ & $6.44 \pm 0.92 \mathrm{c}$ & $1.76 \pm 0.03 \mathrm{~b}$ & $7.55 \pm 0.10 \mathrm{c}$ \\
\hline
\end{tabular}

${ }^{\mathrm{z}} \mathrm{R}_{\mathrm{N}}=$ red native; $\mathrm{O}_{\mathrm{N}}=$ orange native; $\mathrm{Y}_{\mathrm{N}}=$ yellow native; $\mathrm{P}_{\mathrm{N}}=$ purple native; $\mathrm{LR}_{\mathrm{H}}=$ light red hybrid; $\mathrm{LO}_{\mathrm{H}}=$ light orange hybrid; $\mathrm{C}_{\mathrm{H}}=$ chartreuse hybrid; $\mathrm{B}_{\mathrm{H}}=$ black hybrid.

${ }^{\mathrm{y}}$ Values followed by the same letter in each column are not significantly different among each other according to the Tukey multiple comparison test $(\alpha=0.05)$. 
which carotenoids were detected $(400-500 \mathrm{~nm})$. This suggested that the most appropriate method to measure antioxidant capacity in tomatoes was ABTS followed by CUPRAC and then DPPH.

The $Y_{N}$ genotype had the greatest antioxidant capacity in the hydrophilic fractions from the three determination methods $\left(0.054,12.9\right.$, and $11.08 \mu \mathrm{mol} \cdot \mathrm{g}^{-1} \mathrm{TE}$ for DPPH, CUPRAC, and ABTS, respectively). For the lipophilic fractions, greater antioxidant capacities were observed among the red genotypes. The $R_{N}$ genotype had the greatest lipophilic antioxidant capacity with values of 0.0126 (DPPH), 5.20 (CUPRAC), and 2.05 (ABTS) $\mu \mathrm{mol} \cdot \mathrm{g}^{-1} \mathrm{TE}$.

\section{Hydrophilic antioxidants}

Vitamin c. Ascorbic acid levels were greatest in the $\mathrm{R}_{\mathrm{N}}$ and $\mathrm{O}_{\mathrm{N}}$ genotypes [665 and $472 \mu \mathrm{g} \cdot \mathrm{g}^{-1}$, respectively (Table 3)] and the lowest was in the genotype $\mathrm{Y}_{\mathrm{N}}$ at $3.4( \pm 0.1) \mu \mathrm{g} \cdot \mathrm{g}^{-1}$. Hernández-Suárez et al. (2008) found ascorbic acid levels in Dorothy, Boludo, and Dunkan cultivars of Tenerife-grown tomatoes of 138 to $157 \mu \mathrm{g} \cdot \mathrm{g}^{-1}$. In addition, according to Gould (1992), cultivars could be considered a significant source of ascorbic acid with contents higher than $200 \mu \mathrm{g} \cdot \mathrm{g}^{-1}$; on this basis, five of the eight genotypes analyzed in this work $\left[\mathrm{C}_{\mathrm{H}}\right.$, $\mathrm{LR}_{\mathrm{H}}, \mathrm{O}_{\mathrm{N}}, \mathrm{P}_{\mathrm{N}}$, and $\mathrm{R}_{\mathrm{N}}$ ] would be considered a significant source of ascorbic acid because they had values $>200 \mu \mathrm{g} \cdot \mathrm{g}^{-1}$. At physiological $\mathrm{pH}$, vitamin $\mathrm{C}$ exists as monoanion form called ascorbate, which has proven roles in stress tolerance in tomato and fulfills numerous roles, mainly through its antioxidant potential (Baldet et al., 2013).

Total polyphenols. The $Y_{N}$ genotype had the greatest polyphenol content when compared with the rest of the genotypes $\left[64.1 \mu \mathrm{g} \cdot \mathrm{g}^{-1}\right.$ gallic acid equivalents vs. $10.2-49.8$ $\mu \mathrm{g} \cdot \mathrm{g}^{-1}$ gallic acid equivalents (Table 3)], as well as the greatest total antioxidant capacity and antioxidant capacity of the hydrophilic fractions. We proposed that this genotype did not need to develop high levels of vitamin $\mathrm{C}$ as a defense response against abiotic stress because of its high polyphenol content. Our results also indicate that polyphenols have a greater overall contribution to antioxidant capacity when compared with carotenoids and other antioxidants. Barros et al. (2012) determined the polyphenol content in red and yellow tomato cultivars from Portugal and found greater levels in the yellow genotype (54.23 $\mu \mathrm{g} \cdot \mathrm{g}^{-1}$ gallic acid equivalents). Therefore, it was suggested that there was a relationship between the content of phenolic compounds and yellow coloration. It also was proposed that polyphenol contents had been reduced as a result of plant domestication, because wild genotypes contained greater contents of these compounds (Di Paola Naranjo et al., 2016). The total polyphenol content also might be correlated with fruit size, because the bigger genotypes of this study $\left(\mathrm{C}_{\mathrm{H}}\right.$ and $\mathrm{P}_{\mathrm{N}}$ ) had the lowest levels. A possible explanation for this could be that smaller fruit genotypes have a larger surface area in relation to their volume and thus require greater protection against environmental changes, particularly in native genotypes. Furthermore, phenolic compounds in tomato fruit are concentrated in the skin (Bovy et al., 2002). The negative correlation between polyphenols and fruit size has been reported previously and it also suggests that development of cultivars of commercial fruit size with high polyphenol contents may be difficult (Hanson et al., 2004).

Flavonoids. Flavonoids are a group of polyphenolic compounds with important anti-inflammatory and antiallergenic effects. The main flavonoids in tomato are quercetin, kaempferol, and myricetin. In addition to carotenoids, flavonoids, which accumulate mainly in the epidermis, play an important role in the color of tomatoes (Karlova et al., 2014). We found the greatest total flavonoid content in genotype $\mathrm{O}_{\mathrm{N}}$, followed by $\mathrm{B}_{\mathrm{H}}$ and $\mathrm{R}_{\mathrm{N}}$ (Table 3). Among flavonoids, anthocyanins are purple pigments whose accumulation increases resistance to pathogens in tomato fruit (Zhang et al., 2013). Here, anthocyanins were found in the $\mathrm{B}_{\mathrm{H}}, \mathrm{P}_{\mathrm{N}}$, and $\mathrm{R}_{\mathrm{N}}$ genotypes [3.15, 1.22, and $0.26 \mu \mathrm{g} \cdot \mathrm{g}^{-1}$, respectively (Table 3 )]. Our results suggest that native genotypes could be used to improve the levels of flavonoids in commercial cultivars.

\section{Lipophilic antioxidants}

Carotenoids. Fruit color is associated with flavor, health, and nutritional content because carotenoids are precursors of various aroma volatiles and play an important role in photoprotection and inhibiting lipid peroxidation. The strong antioxidant capacity, and the multiple benefits to human health, explains why we seek to select tomato genotypes with greater

Table 3. Total polyphenols, total flavonoids, total anthocyanins, and chlorophyll a and b in selected tomato genotypes. Values represent the means from three biological replicates of 27 fruit each. All values are expressed in a fresh weight basis.

\begin{tabular}{|c|c|c|c|c|c|c|c|}
\hline & $\begin{array}{l}\text { Polyphenols } \\
\text { (gallic acid } \\
\text { equivalents) }\end{array}$ & $\begin{array}{c}\text { Flavonoids } \\
\text { (quercetin } \\
\text { equivalents) }\end{array}$ & Anthocyanins & Chlorophyll a & Chlorophyll b & Total chlorophyll & Vitamin C \\
\hline Genotype $^{z}$ & \multicolumn{7}{|c|}{ Mean \pm SE $\left(\mu g \cdot g^{-1}\right)$} \\
\hline $\mathrm{O}_{\mathrm{N}}$ & $49.8 \pm 6.6 b$ & $1.08 \pm 0.08 \mathrm{a}$ & nd & $14 \pm 0.3 \mathrm{~d}$ & $8.9 \pm 1 b$ & $22 \pm 0.7 \mathrm{c}$ & $472 \pm 0.9 \mathrm{~b}$ \\
\hline $\mathrm{Y}_{\mathrm{N}}$ & $64.1 \pm 1.9 \mathrm{a}$ & $0.02 \pm 0.01 \mathrm{e}$ & nd & nd & nd & nd & $0.34 \pm 0.1 \mathrm{~g}$ \\
\hline $\mathrm{P}_{\mathrm{N}}$ & $21.0 \pm 5.6 \mathrm{e}$ & $0.06 \pm 0.01 \mathrm{e}$ & $1.22 \pm 0.3 \mathrm{~b}$ & $227 \pm 0.6 \mathrm{a}$ & $69 \pm 1.4 \mathrm{a}$ & $296 \pm 1.7 \mathrm{a}$ & $222 \pm 1 \mathrm{~d}$ \\
\hline $\mathrm{LO}_{\mathrm{H}}$ & $34.3 \pm 9.8 \mathrm{~d}$ & $0.13 \pm 0.01 \mathrm{~d}$ & nd & nd & nd & nd & $163 \pm 2.4 \mathrm{e}$ \\
\hline $\mathrm{C}_{\mathrm{H}}$ & $10.2 \pm 2.1 \mathrm{f}$ & nd & nd & $155 \pm 0.02 b$ & $64 \pm 0.06 \mathrm{a}$ & $219 \pm 0.15 b$ & $339 \pm 7.1 \mathrm{c}$ \\
\hline $\mathrm{B}_{\mathrm{H}}$ & $39.7 \pm 0.41 \mathrm{c}$ & $0.52 \pm 0.14 b$ & $3.15 \pm 1.0 \mathrm{a}$ & $28 \pm 0.02 \mathrm{c}$ & $2.9 \pm 0.1 \mathrm{~b}$ & $31 \pm 0.07 \mathrm{c}$ & $7.92 \pm 12.4 \mathrm{f}$ \\
\hline
\end{tabular}

${ }^{\mathrm{z}} \mathrm{R}_{\mathrm{N}}=$ red native; $\mathrm{O}_{\mathrm{N}}=$ orange native; $\mathrm{Y}_{\mathrm{N}}=$ yellow native; $\mathrm{P}_{\mathrm{N}}=$ purple native; $\mathrm{LR}_{\mathrm{H}}=$ light red hybrid; $\mathrm{LO}_{\mathrm{H}}=$ light orange hybrid; $\mathrm{C}_{\mathrm{H}}=$ chartreuse hybrid; $\mathrm{B}_{\mathrm{H}}=$ black hybrid.

${ }^{\mathrm{y}}$ Values followed by the same letter in each column are not significantly different among each other according to the Tukey multiple comparison test $(\alpha=0.05)$.

nd $=$ not detected. 
contents of carotenoids and other antioxidants (Klee and Giovannoni, 2011; Namitha et al., 2011).

Lycopene is among the main functional compounds in tomato fruit because of its strong antioxidant role (Stahl and Sies, 2003). Here, significant differences were found in the levels of lycopene (Table 4$)$, which ranged from $3.59( \pm 0.007)$ to $44.57( \pm 0.99) \mu \mathrm{g} \cdot \mathrm{g}^{-1}$. The greatest levels were found in the $\mathrm{R}_{\mathrm{N}}$ genotype $\left(44.57 \mu \mathrm{g} \cdot \mathrm{g}^{-1}\right.$ ) followed by $\mathrm{LR}_{\mathrm{H}}$ and $\mathrm{B}_{\mathrm{H}}$ genotypes; the $\mathrm{Y}_{\mathrm{N}}$ and $\mathrm{C}_{\mathrm{H}}$ genotypes had the lowest levels. The values found in this study were consistent with those reported by Lewinsohn et al. (2005), who found levels of 0.04 to $63.6 \mu \mathrm{g} \cdot \mathrm{g}^{-1}$ of lycopene. Lycopene can decrease the formation of erythema

Table 4. Tocopherol and carotenoid contents of tomato genotypes. Values represent the means from three biological replicates of 27 fruit each. All values are expressed in a fresh weight basis.

\begin{tabular}{|c|c|c|c|c|c|c|c|}
\hline \multirow[b]{2}{*}{ Genotype ${ }^{z}$} & $\alpha$-Tocopherol & $\beta$-Tocopherol & $\delta$-Tocopherol & $\gamma$-Tocopherol & Lycopene & $\beta$-Carotene & Lutein \\
\hline & \multicolumn{7}{|c|}{ Mean \pm SE $\left(\mu \mathrm{g} \cdot \mathrm{g}^{-1}\right)$} \\
\hline $\mathrm{O}_{\mathrm{N}}$ & $5.51 \pm 0.04 \mathrm{~b}$ & $0.41 \pm 0.04 \mathrm{c}$ & $0.01 \pm 0.003 \mathrm{c}$ & $0.51 \pm 0.004 \mathrm{~b}$ & $11.0 \pm 0.11 \mathrm{~d}$ & $1.41 \pm 0.03 \mathrm{~b}$ & $0.47 \pm 0.106 \mathrm{~b}$ \\
\hline $\mathrm{P}_{\mathrm{N}}$ & $1.23 \pm 0.02 \mathrm{e}$ & $0.22 \pm 0.01 \mathrm{~d}$ & $0.01 \pm 0.008 \mathrm{c}$ & $0.10 \pm 0.005 \mathrm{c}$ & $11.5 \pm 0.13 \mathrm{~d}$ & $0.21 \pm 0.13 \mathrm{c}$ & $0.40 \pm 0.011 \mathrm{~d}$ \\
\hline $\mathrm{LR}_{\mathrm{H}}$ & $1.76 \pm 0.06 \mathrm{~d}$ & $0.57 \pm 0.00 \mathrm{~b}$ & $0.13 \pm 0.031 \mathrm{a}$ & $2.09 \pm 0.026 \mathrm{a}$ & $26.7 \pm 0.09 \mathrm{~b}$ & $2.82 \pm 0.02 \mathrm{a}$ & $0.54 \pm 0.017 \mathrm{c}$ \\
\hline $\mathrm{LO}_{\mathrm{H}}$ & $7.90 \pm 0.1 \mathrm{a}$ & $0.76 \pm 0.05 \mathrm{a}$ & $0.16 \pm 0.051 \mathrm{a}$ & $2.23 \pm 0.238 \mathrm{a}$ & $10.1 \pm 0.02 \mathrm{~d}$ & $1.37 \pm 0.26 \mathrm{~b}$ & $0.41 \pm 0.002 \mathrm{~d}$ \\
\hline
\end{tabular}

${ }^{\mathrm{z}} \mathrm{R}_{\mathrm{N}}=$ red native; $\mathrm{O}_{\mathrm{N}}=$ orange native; $\mathrm{Y}_{\mathrm{N}}=$ yellow native; $\mathrm{P}_{\mathrm{N}}=$ purple native; $\mathrm{LR}_{\mathrm{H}}=$ light red hybrid; $\mathrm{LO}_{\mathrm{H}}=$ light orange hybrid; $\mathrm{C}_{\mathrm{H}}=$ chartreuse hybrid; $\mathrm{B}_{\mathrm{H}}=$ black hybrid.

${ }^{y}$ Values followed by the same letter in each column are not significantly different among each other according to the Tukey's multiple comparison test $(\alpha=0.05)$.

nd $=$ not detected.

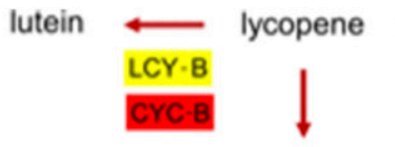

$\beta$-carotene

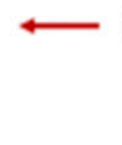

phytoene

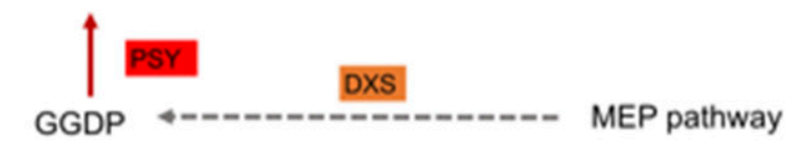

$\begin{array}{llllllll}\mathbf{R}_{*} & \mathrm{O}_{\mathrm{N}} & \mathrm{Y}_{\mathrm{N}} & \mathbf{P}_{\mathrm{N}} & \mathrm{LR}_{\mathrm{H}} & \mathrm{LO} & \mathrm{C}_{\mathrm{H}} & \mathrm{B}_{\mathrm{H}}\end{array}$
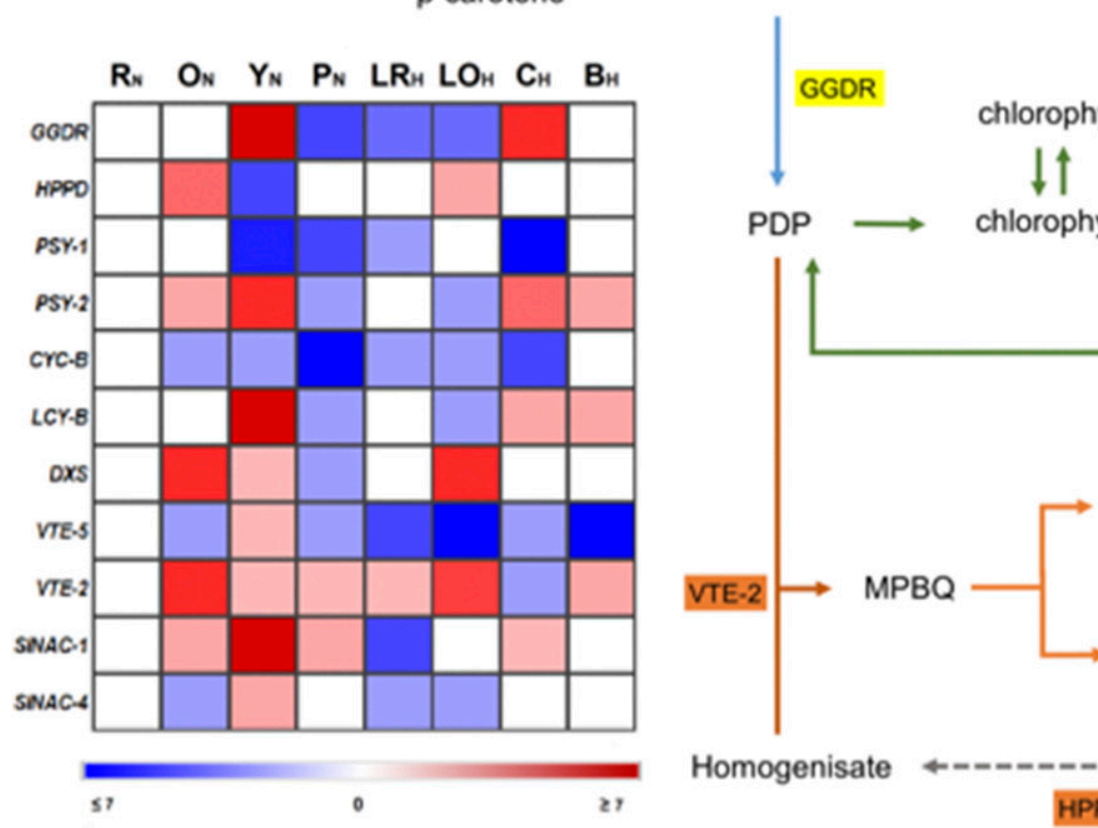

Homogenisate

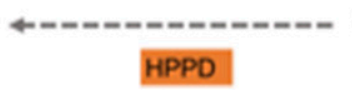

Shikimate pathway

Fig. 2. Heat map representation of $\log 2$-fold change in RNA expression of carotenoid and tocopherol-related genes and NAC transcription factors in tomato compared with the native red $\left(\mathrm{R}_{\mathrm{N}}\right)$ genotype. Tocopherol, chlorophyll, and carotenoid biosynthetic pathways adapted from Almeida et al. (2016) and Lira et al. (2016) are indicated in orange, green, and red, respectively. The genes $(G G D R=$ geranylgeranyl reductase; $H P P D=4$-hydroxyphenylpyruvate dioxygenase; $P S Y$ $1=$ phytoene synthase $1 ; P S Y-2=$ phytoene synthase $2 ; C Y C-B=$ chromoplast-specific lycopene $\beta$-cyclase; $L C Y$ - $B=1$ ycopene $\beta$-cyclase; $D X S=1$-deoxy-Dxylulose phosphate synthase; $V T E-5=$ phytol kinase; $V T E-2=$ homogentisate phytyl transferase; MEP pathway $=$ non-mevalonate pathway; PP/PDP $=$ phytyl diphosphate; GGDP = geranylgeranyl diphosphate; $\mathrm{MPBQ}=2$-methyl-6-phytyl-1,4-benzoquinol; and DMBQ = 2,3-dimethyl-6-geranylgeranylbenzoquinol) are indicated by the color of the genotype that showed the greatest transcript levels (red, orange, or yellow): $O_{N}=$ orange native; $Y_{N}=$ yellow native; $P_{N}=$ purple native; $\mathrm{LR}_{\mathrm{H}}=$ light red hybrid; $\mathrm{LO}_{\mathrm{H}}=$ light orange hybrid; $\mathrm{C}_{\mathrm{H}}=$ chartreuse hybrid; $\mathrm{B}_{\mathrm{H}}=$ black hybrid. 
of the skin and inhibit prostate, breast, colorectal, lung, and pancreatic cancer. Greater intake of lycopene is recommended for patients with cancer and cardiovascular disease $[35-75 \mathrm{mg}$ daily (Stahl and Sies, 2003)].

$\beta$-carotene is a red-orange pigment and a precursor of vitamin A considered an essential compound for vision. It also prevents photo oxidative damage and sunburn (Almeida et al., 2014; Lewinsohn et al., 2005; Stahl and Sies, 2003). In this study, $\beta$-carotene levels were $80 \%$ to $90 \%$ lower than lycopene levels, ranging from 0.14 to $3.0 \mu \mathrm{g} \cdot \mathrm{g}^{-1}$. The greatest $\beta$-carotene levels were found in the $R_{N}$ and $\mathrm{LR}_{\mathrm{H}}$ genotypes (Table 4).

Lutein was high in the $\mathrm{Y}_{\mathrm{N}}$ genotype $\left[1.12 \pm 0.01 \mu \mathrm{g} \cdot \mathrm{g}^{-1}\right.$ (Table 4)]. Lutein is a yellow pigment synthesized in both chloroplasts and chromoplasts and promotes eye and skin health (Almeida et al., 2014). The values seen here were similar to those of Perry et al. (2009), who found a content of 0.32 $\mu \mathrm{g} \cdot \mathrm{g}^{-1}$ in round tomatoes.

Tocopherols. $\alpha$-tocopherol, the most abundant form in tomatoes, was greatest in the orange genotypes (7.89 and 5.5 $\mu \mathrm{g} \cdot \mathrm{g}^{-1}$ in $\mathrm{O}_{\mathrm{N}}$ and $\mathrm{LO}_{\mathrm{H}}$ genotypes, respectively). This was close to values reported for Naomi red cherry tomato $\left(7.4 \mu \mathrm{g} \cdot \mathrm{g}^{-1}\right)$, a genotype that is rich in $\alpha$-tocopherol (Zanfini et al., 2010). In our study, $\beta, \delta$, and $\gamma$ tocopherol content was greatest in $\mathrm{LR}_{\mathrm{H}}$ and $\mathrm{LO}_{\mathrm{H}}$ genotypes (Table 4). These results support the use of tomato genotypes of different color either directly as food sources or in breeding programs to rescue functional compounds such as carotenoids, tocopherols, anthocyanins and vitamin $\mathrm{C}$.

\section{Chlorophylls}

Some mature tomato genotypes may contain chlorophyll because it does not completely degrade during ripening (Carrillo-López and Yahia, 2014). We found the greatest levels of chlorophyll a in the $\mathrm{B}_{\mathrm{H}}$ genotype, followed by $\mathrm{P}_{\mathrm{N}}[0.276$ and $0.227 \mathrm{mg} \cdot \mathrm{g}^{-1}$, respectively (Table 3$\left.)\right]$. Chlorophyll b was greater in the $\mathrm{P}_{\mathrm{N}}$ and $\mathrm{C}_{\mathrm{H}}$ genotypes $\left(0.069\right.$ and $0.064 \mathrm{mg} \cdot \mathrm{g}^{-1}$, respectively). In terms of total chlorophyll content, significant differences were found between genotypes, with the content greatest in $\mathrm{B}_{\mathrm{H}}\left(0.305 \mathrm{mg} \cdot \mathrm{g}^{-1}\right)$ followed by $\mathrm{P}_{\mathrm{N}}\left(0.296 \mathrm{mg} \cdot \mathrm{g}^{-1}\right)$, $\mathrm{C}_{\mathrm{H}}\left(0.219 \mathrm{mg} \cdot \mathrm{g}^{-1}\right)$, and finally $\mathrm{O}_{\mathrm{N}}$ genotype $\left(0.022 \mathrm{mg} \cdot \mathrm{g}^{-1}\right)$. Costache et al. (2012) reported an average of $0.25 \mathrm{mg} \cdot \mathrm{g}^{-1}$ of total chlorophylls in cherry genotypes. The high levels of chlorophylls, carotenoids (mainly lycopene), and anthocyanins suggested that the black and purple color of these genotypes was the result of a combination of chlorophylls with these pigments.

\section{Expression of enzyme-encoding genes of the carotenoid and tocopherol biosynthetic pathways}

Chlorophylls, carotenoids, and tocopherols are isoprenoidderived compounds that share a common precursor, geranylgeranyl diphosphate (Quadrana et al., 2013). The chlorophyll and tocopherol prenyl side chains derive from phytyl diphosphate (PDP), which in turn is generated by GGDR. PDP for tocopherol biosynthesis also can originate from phytol kinase (VTE5) phosphorylation of phytol to phytyl-phosphate. Recent evidence indicates that PDP for tocopherol biosynthesis is mostly supplied by chlorophyll degradation (Almeida et al., 2016; Lira et al., 2016).

In this work, the transcript levels of $P S Y 1$ were greater in $\mathrm{R}_{\mathrm{N}}$, $\mathrm{LR}_{\mathrm{H}}$, and $\mathrm{B}_{\mathrm{H}}$ genotypes, whereas the lowest levels were found in the $\mathrm{Y}_{\mathrm{N}}$ and $\mathrm{C}_{\mathrm{H}}$ genotypes (Fig. 2; Table 5). According to Lois et al. (2000), the increase in expression of PSY1 during fruit ripening is correlated with lycopene accumulation and is induced by ethylene. The $C Y C-B$ transcript levels were greatest in genotypes with greater lycopene and $\beta$-carotene levels. Hwang et al. (2016) found a greater $C Y C-B$ expression in orange genotypes with greater $\beta$-carotene content, suggesting a relationship between $C Y C-B$ expression and the levels of this carotenoid. A similar trend was found here with the genotypes with greater levels of $\beta$-carotene $\left(\mathrm{R}_{\mathrm{N}}, \mathrm{LR}_{\mathrm{H}}, \mathrm{O}_{\mathrm{N}}, \mathrm{LO}_{\mathrm{H}}\right.$, and $\left.\mathrm{B}_{\mathrm{H}}\right)$ also having significantly greater $C Y C-B$ transcript levels.

Table 5. Relative mRNA expression values of carotenoid and tocopherol-related genes and NAC transcription factors in tomato genotypes compared with the $\mathrm{R}_{\mathrm{N}}$ genotype.

\begin{tabular}{|c|c|c|c|c|c|c|c|c|}
\hline \multirow[b]{3}{*}{$\mathrm{Gene}^{\mathrm{z}}$} & \multicolumn{8}{|c|}{ Genotype $^{y}$} \\
\hline & $\mathrm{R}_{\mathrm{N}}$ & $\mathrm{N}_{\mathrm{O}}$ & $\mathrm{Y}_{\mathrm{N}}$ & $\mathrm{P}_{\mathrm{N}}$ & $\mathrm{LR}_{\mathrm{H}}$ & $\mathrm{LO}_{\mathrm{H}}$ & $\mathrm{C}_{\mathrm{H}}$ & $\mathrm{B}_{\mathrm{H}}$ \\
\hline & \multicolumn{8}{|c|}{ Mean \pm SE } \\
\hline$\overline{G G D R}$ & $000 \pm 0.00 \mathrm{~b}^{\mathrm{x}}$ & $640 \pm 0.5 \mathrm{~b}$ & $28.314 \pm 1.7 \mathrm{a}$ & $397 \pm 0.03 \mathrm{~b}$ & $0.837 \pm$ & $740 \pm 0.13 b$ & $15.127 \pm 0$ & $1.624 \pm 0$ \\
\hline PSY1 & $1.000 \pm 0.00 \mathrm{a}$ & $0.833 \pm 0$ & $9 \mathrm{c}$ & $\pm 0.33 \mathrm{~b}$ & $0.787 \pm$ & $26 \pm$ & $0 \mathrm{~d}$ & $6 \mathrm{a}$ \\
\hline$P S Y 2$ & $1.000 \pm 0.00 \mathrm{c}$ & $1.223 \pm 0.19 \mathrm{c}$ & $5.105 \pm 0.45 \mathrm{a}$ & $0.968 \pm 0.15 b$ & $1.405 \pm 0.38 \mathrm{c}$ & $0.485 \pm 0$ & $3.916 \pm 0.6 b$ & $1.266 \pm 0.09 \mathrm{c}$ \\
\hline$C Y C-B$ & $1.000 \pm 0.00 \mathrm{a}$ & $0.784 \pm 0.10 \mathrm{a}$ & $0.611 \pm 0.02 b$ & $\pm 0.15 \mathrm{c}$ & $0.792 \pm 0.15 \mathrm{a}$ & $0.808 \pm$ & $0.357 \pm 0$ & $1.040 \pm 0.03 \mathrm{a}$ \\
\hline$D X S$ & $1.000 \pm 0.00 \mathrm{c}$ & $5.072 \pm 1.50 \mathrm{a}$ & $2.067 \pm 0.54 \mathrm{~b}$ & $0.923 \pm 0.31 \mathrm{c}$ & $2.105 \pm 0.82 b$ & $5.056 \pm 1$ & $1.680 \pm 0$ & $1.844 \pm 0.67 \mathrm{~b}$ \\
\hline$V T E-5$ & $1.000 \pm 0.00 \mathrm{~b}$ & $0.495 \pm 0.16 \mathrm{c}$ & $1.778 \pm 0.56 \mathrm{a}$ & $0.734 \pm 0.16 b$ & $0.256 \pm 0.03 \mathrm{~d}$ & $0.314 \pm 0.02 \mathrm{~d}$ & $1.456 \pm 0.37 \mathrm{a}$ & $0.353 \pm 0.07 \mathrm{~d}$ \\
\hline$V T E-2$ & $1.000 \pm 0.00 \mathrm{c}$ & $4.512 \pm 0.38 \mathrm{a}$ & $2.089 \pm 0.99 \mathrm{~b}$ & $2.474 \pm 0.63 b$ & $2.664 \pm 0.3 b$ & $5.064 \pm 0.41 \mathrm{a}$ & $0.964 \pm 0.39 \mathrm{c}$ & $2.921 \pm 1.0 \mathrm{ab}$ \\
\hline SINAC-1 & $1.000 \pm 0.00 \mathrm{c}$ & $2.881 \pm 0.67 b$ & $6.833 \pm 0.22 \mathrm{a}$ & $3.056 \pm 1.02 \mathrm{~b}$ & $0.291 \pm 0.01 \mathrm{~d}$ & $0.894 \pm 0.08 \mathrm{c}$ & $1.469 \pm 0.25 \mathrm{c}$ & $1.161 \pm 0.11 \mathrm{c}$ \\
\hline SINAC-4 & $1.000 \pm 0.00 \mathrm{~b}$ & $1.396 \pm 0.18 b$ & $1.884 \pm 0.13 \mathrm{a}$ & $0.760 \pm 0.24 \mathrm{c}$ & $0.422 \pm 0.04 \mathrm{~d}$ & $0.596 \pm 0.06 \mathrm{c}$ & $1.163 \pm 0.25 \mathrm{~b}$ & $0.614 \pm 0.16 \mathrm{c}$ \\
\hline
\end{tabular}

${ }^{\mathrm{z}} G G D R=$ geranylgeranyl reductase; $H P P D=4$-hydroxyphenylpyruvate dioxygenase; $P S Y-1=$ phytoene synthase $1 ; P S Y-2=$ phytoene synthase 2; $C Y C-B=$ chromoplast-specific lycopene $\beta$-cyclase; $L C Y-B=$ lycopene $\beta$-cyclase; $D X S=1$-deoxy-D-xylulose phosphate synthase; $V T E-5=$ phytol kinase; $V T E-2=$ homogentisate phytyl transferase).

${ }^{\mathrm{y}} \mathrm{R}_{\mathrm{N}}=$ red native; $\mathrm{O}_{\mathrm{N}}=$ orange native; $\mathrm{Y}_{\mathrm{N}}=$ yellow native; $\mathrm{P}_{\mathrm{N}}=$ purple native; $\mathrm{LR}_{\mathrm{H}}=$ light red hybrid; $\mathrm{LO}_{\mathrm{H}}=$ light orange hybrid; $\mathrm{C}_{\mathrm{H}}=$ chartreuse hybrid; $\mathrm{B}_{\mathrm{H}}=$ black hybrid.

${ }^{x}$ Values followed by the same letter in each column are not significantly different among each other according to the Tukey's multiple comparison test $(\alpha=0.05)$. 
PSY2, found exclusively in chloroplasts, was five times greater in the $\mathrm{Y}_{\mathrm{N}}$ and $\mathrm{C}_{\mathrm{H}}$ genotypes than in the $\mathrm{R}_{\mathrm{N}}$ genotype. The transcript levels of $L C Y-B$ were also five times greater in the $\mathrm{Y}_{\mathrm{N}}$ genotype than in the $\mathrm{R}_{\mathrm{N}}$ genotype, which also had greater lutein contents. These results suggest that the LCY-B enzyme was more involved in the conversion of $\delta$-carotene to $\alpha$-carotene for lutein synthesis than CYC-B (Namitha et al., 2011).

Regarding the genes of the tocopherol pathway, the transcript levels of $G G D R$ were greatest in the $\mathrm{Y}_{\mathrm{N}}$ and $\mathrm{C}_{\mathrm{H}}$ genotypes. VTE-5, associated with chlorophyll recycling, had a 1.8-fold greater relative expression in the $\mathrm{Y}_{\mathrm{N}}$ and $\mathrm{C}_{\mathrm{H}}$ genotypes compared with the $\mathrm{R}_{\mathrm{N}}$ genotype. In contrast, the transcript levels of $H P P D, D X S$, and $V T E-2$ were greater in $\mathrm{O}_{\mathrm{N}}$ and $\mathrm{LO}_{\mathrm{H}}$ genotypes, which also had the greatest tocopherol contents. Almeida et al. (2014) report that the expression of $V T E-2$ increases with tocopherol synthesis.

\section{NAC transcription factors}

SINAC1 is the most-studied NAC transcription factor in tomato. Ma et al. (2014) reported that overexpression of SINAC1 resulted in reduced carotenoids by altering carotenoid pathway flux and decreasing ethylene synthesis, leading to yellow and orange mature fruit. In the present study, we found a greater expression of SINAC1 in both native and hybrid yellow fruit with lower lycopene and $\beta$-carotene levels, followed by those with orange, dark coloration, and finally red fruit (Table 5). Our results confirmed that SINAC1 expression was highly associated with carotenoid content and color of the fruit.

By comparison, SINAC4 has been reported to play an important role in carotenoid accumulation during tomato fruit ripening, acting as a positive regulator by modulating the hormone ethylene and therefore carotenoid pigmentation. Zhu et al. (2014) reported that fruit from RNAi transgenic tomato plants displayed orange color in both the pericarp and placenta, which implied decreased accumulation of lycopene and elevated $\beta$-carotene. A reduced expression of the gene PSY1 was reported, with the chromoplast and chloroplast lycopene $\beta$-cyclases $(C Y C-B$ and $L C Y-B)$ being upregulated in SINAC4 RNAi fruit as compared with controls. In the present study, a greater expression of SINAC4 was found in yellow fruit, suggesting that SINAC4 might be associated with yellow carotenoid lutein production, which is regulated mainly by LCY-B (Namitha et al., 2011). Moreover, a greater expression in native genotypes compared with hybrid genotypes suggests that although SINAC4 has been associated with coloration, it also has been reported that it responds to several stress factors such as dehydration (Zhu et al., 2014). Native genotypes show greater biotic and abiotic stress responses, which allow them to grow in soils with limited moisture availability and tolerate high temperatures.

\section{PCA and Pearson correlation coefficient analysis}

Tomato fruit of different colors are an interesting model to understand the isoprenoid-metabolic cross-talk of the tocopherol, chlorophyll, and carotenoid pathways. In this work, we found that greater levels of specific antioxidants were associated with particular colorations of tomato fruit. PCA was carried out to study the correlation between all studied parameters (Fig. 3A). Red genotypes $\left(R_{N}\right.$ and $\left.L_{H}\right)$ were associated with lycopene, $\beta$-carotene, lipophilic antioxidant capacity, total polyphenols, vitamin $\mathrm{C}$, and greater relative transcript expression of $P S Y 1$ and $C Y C-B$ (both chromoplastic) but not with tocopherols, which indicated that in these genotypes, carotenoids made a greater contribution to lipophilic antioxidant capacity (Table 6$)$. Orange genotypes $\left(\mathrm{O}_{\mathrm{N}}\right.$ and $\mathrm{LO}_{\mathrm{H}}$ ) correlated with tocopherols, flavonoids, VTE-2, HPPD, and $D X S$ expression. A positive correlation between $H P P D$ and $V T E-2$, and negative correlations between PSY1 and VTE-5 $(-0.8192)$ and between lycopene and chlorophyll $(-0.6209)$ suggested a balance between chlorophylls, tocopherols, and carotenoids. These correlations were consistent in light of the chloroplast-to-chromoplast transition during fruit ripening that results in massive chlorophyll degradation and lycopene accumulation. The results of this study suggested compensation between antioxidant levels, which in turn was associated with a

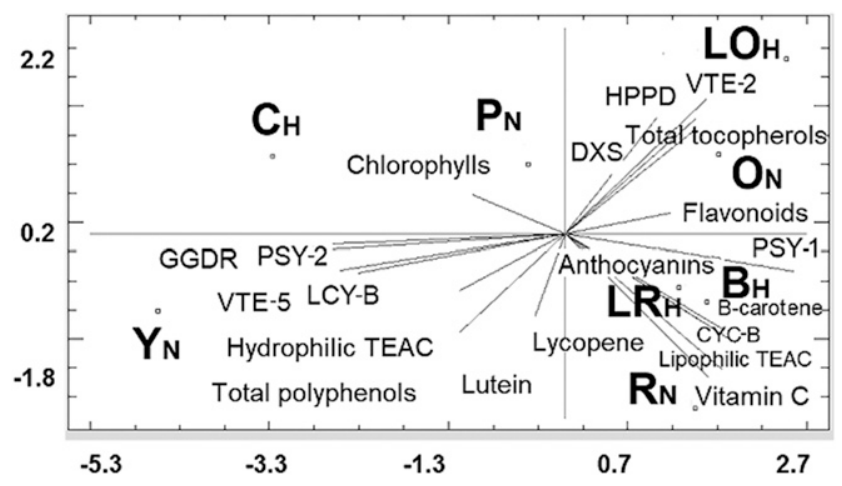

Fig. 3. Principal component analysis showing the correlation between all studied parameters in tomato genotypes $\left(\mathrm{O}_{\mathrm{N}}=\right.$ orange native; $\mathrm{Y}_{\mathrm{N}}=$ yellow native; $\mathrm{P}_{\mathrm{N}}=$ purple native; $\mathrm{LR}_{\mathrm{H}}=$ light red hybrid; $\mathrm{LO}_{\mathrm{H}}=$ light orange hybrid; $\mathrm{C}_{\mathrm{H}}=$ chartreuse hybrid; $\mathrm{B}_{\mathrm{H}}=$ black hybrid); TEAC = Troloxequivalent antioxidant capacity; $G G D R=$ geranylgeranyl reductase; $H P P D=$ 4-hydroxyphenylpyruvate dioxygenase; $P S Y-1=$ phytoene synthase 1; $P S Y-2=$ phytoene synthase $2 ; C Y C-B=$ chromoplast-specific lycopene $\beta$-cyclase; $L C Y$ - $B=1$ lycopene $\beta$-cyclase; $D X S=1$-deoxy-D-xylulose phosphate synthase; $V T E-5=$ phytol kinase; $V T E-2=$ homogentisate phytyl transferase.

Table 6. Statistically significant Pearson product moment correlations $(P$ values below 0.05). These correlation coefficients range between -1 and +1 and measure the strength of the linear relationship between the variables.

\begin{tabular}{lc}
\hline Parameter & $\begin{array}{c}\text { Correlation } \\
\text { coefficient }\end{array}$ \\
\hline Total polyphenols vs. lutein & 0.94 \\
Total polyphenols vs. hydrophilic TEAC & 0.96 \\
Lycopene vs. $\beta$-carotene & 0.89 \\
Lycopene vs. lipophilic TEAC & 0.89 \\
$\beta$-carotene vs. lipophilic TEAC & 0.89 \\
Total tocopherols vs. HPPD & 0.91 \\
Total tocopherols vs. VTE-2 & 0.85 \\
GGDR vs. VTE-5 & 0.87 \\
GGDR vs. LCY-B & 0.96 \\
GGDR vs. PSY-2 & 0.99 \\
LCY-B vs. PSY-2 & 0.97 \\
HPPD vs. VTE-2 & 0.92
\end{tabular}

$\overline{\text { TEAC }}=$ Trolox-equivalent antioxidant capacity; HPPD $=4$ hydroxyphenylpyruvate dioxygenase; VTE-2 = homogentisate phytyl transferase; GGDR = geranylgeranyl reductase; VTE-5 = phytol kinase; LCY-B = lycopene $\beta$-cyclase; PSY-2 = phytoene synthase 2. 
particular color of the fruit. Although the $\mathrm{B}_{\mathrm{H}}$ genotype was associated with anthocyanins, the $Y_{N}$ genotype was associated with lutein, total polyphenols, hydrophilic antioxidant capacity, and PSY2, $L C Y-B, V T E-5$, and GGDR expression. The red genotypes analyzed here were a source of both lycopene, associated with greater PSY1 expression, and $\beta$-carotene, whose content was associated with greater $C Y C-B$ expression, whereas the $\mathrm{Y}_{\mathrm{N}}$ genotype presented the greatest total polyphenol content, resulting in a greater in vitro antioxidant capacity of the hydrophilic fraction. Native genotypes of different color are a significant source of functional compounds that have been lost in commercial red genotypes through selection processes. These genotypes could be used either directly as food or in breeding programs to recover greater levels of functional compounds, such as carotenoids, tocopherols, anthocyanins, and vitamin $\mathrm{C}$.

\section{Literature Cited}

Almeida, J., R. Asís, V. Noel Molineri, I. Sestari, B.S. Lira, F. Carrari, L.E. Peres, and M. Rossi. 2014. Fruits from ripening impaired, chlorophyll degraded and jasmonate insensitive tomato mutants have altered tocopherol content and composition. Phytochemistry 111: 72-83.

Almeida, J., M.D.S. Azevedo, L. Spicher, G. Glauser, K. vom Dorp, L. Guyer, A. del Valle Carranza, R. Asis, A. Pereira de Souzam, M. Buckeridge, D. Demarco, C. Bres, C. Rothan, L.E. Pereira, S. Hörtensteiner, F. Kessler, P. Dörmann, F. Carrari, and D. Demarco. 2016. Down-regulation of tomato PHYTOL KINASE strongly impairs tocopherol biosynthesis and affects prenyllipid metabolism in an organ-specific manner. J. Expt. Bot. 67:919-934.

Baldet, P., C. Bres, Y. Okabe, J.P. Mauxion, D. Just, C. Bournonville, K. Mori, H. Ezura, C. Ferrand, and C. Rothan. 2013. Investigating the role of vitamin $\mathrm{C}$ in tomato through TILLING identification of ascorbate-deficient tomato mutants. Plant Biotechnol. 30:309314.

Barros, L., M. Dueñas, J. Pinela, A.M. Carvalho, C.S. Buelga, and I.C. Ferreira. 2012. Characterization and quantification of phenolic compounds in four tomato (Lycopersicon esculentum L.) farmers' varieties in northeastern Portugal homegardens. Plant Foods Hum. Nutr. 67:229-234.

Bovy, A., R. de Vos, M. Kempe, E. Schijlen, M.A. Pertejo, S. Muir, and C. Santos-Buelga. 2002. High-flavonol tomatoes resulting from the heterologous expression of the maize transcription factor genes LC and C1. Plant Cell 14:2509-2526.

Brand-Williams, W., M.E. Cuvelier, and C.L.W.T. Berset. 1995. Use of a free radical method to evaluate antioxidant activity. Lebensm. Wiss. Technol. 28:25-28.

Carrillo-López, A. and E.M. Yahia. 2014. Changes in color-related compounds in tomato fruit exocarp and mesocarp during ripening using HPLC-APcI+-mass spectrometry. J. Food Sci. Technol. 51:2720-2726.

Chang, S., J. Puryear, and J.A. Cairney. 1993. Simple and efficient method for isolating RNA from pine trees. Plant Mol. Biol. Rpt. 11:113-116.

Chang, C.C., M.H. Yang, H.M. Wen, and J.C. Chern. 2002. Estimation of total flavonoid content in propolis by two complementary colorimetric methods. Yao Wu Shi Pin Fen Xi 10:3.

Costache, M.A., G. Campeanu, and G. Neata. 2012. Studies concerning the extraction of chlorophyll and total carotenoids from vegetables. Rom. Biotechnol. Lett. 17:7703-7708.

Di Paola Naranjo, R.D., S. Otaiza, A.C. Saragusti, V. Baroni, A.D.V. Carranza, I.E. Peralta, E.M. Valle, F. Carrari, and R. Asis. 2016. Hydrophilic antioxidants from Andean tomato landraces assessed by their bioactivities in vitro and in vivo. Food Chem. 206:146-155.

Gould, W.A. 1992. Tomato production, processing and technology. CTI Publications, Inc., Baltimore, MD.
Guo, F., W. Zhou, J. Zhang, Q. Xu, and X. Deng. 2012. Effect of the citrus lycopene B-cyclase transgene on carotenoid metabolism in transgenic tomato fruits. PLoS One 7:1-9.

Hanson, P.M., R.Y. Yang, J. Wu, J.T. Chen, D. Ledesma, S.C. Tsou, and T.C. Lee. 2004. Variation for antioxidant activity and antioxidants in tomato. J. Amer. Soc. Hort. Sci. 129:704-711.

Hernández-Suárez, M., E. Rodríguez-Rodríguez, and C. DíazRomero. 2008. Analysis of organic acid content in cultivars of tomato harvested in Tenerife. Eur. Food Res. Technol. 226:423435.

Hwang, I., Y. Kim, J. Han, and I.S. Nou. 2016. Orange color is associated with CYC-B expression in tomato fleshy fruit. Mol. Breed. 36:1-10.

Karlova, R., N. Chapman, K. David, G.C. Angenent, G.B. Seymour, and R.A. de Maagd. 2014. Transcriptional control of the fleshy fruit development and ripening. J. Expt. Bot. 65:4527-4541.

Klee, H.J. and J.J. Giovannoni. 2011. Genetics and control of tomato fruit ripening and quality attributes. Annu. Rev. Genet. 45:41-59.

Lewinsohn, E., Y. Sitrit, E. Bar, Y. Azulay, M. Ibdah, A. Meir, and Y. Tadmor. 2005. Not just colors - Carotenoid degradation as a link between pigmentation and aroma in tomato and watermelon fruit. Trends Food Sci. Technol. 16:407-415.

Lira, B.S., D. Rosado, J. Almeida, A.P. de Souza, M.S. Buckeridge, E. Purgatto, and M. Rossi. 2016. Pheophytinase knockdown impacts carbon metabolism and nutraceutical content under normal growth conditions in tomato. Plant Cell Physiol. 57:642-653.

Liu, L., Z. Shao, M. Zhang, and Q. Wang. 2015. Regulation of carotenoid metabolism in tomato. Mol. Plant 8:28-39.

Lois, L.M., M. Rodriguez-Concepcion, F. Gallego, N. Campos, and A. Boronat. 2000. Carotenoid biosynthesis during tomato fruit development: Regulatory role of 1-deoxy-D-xylulose 5-phosphate synthase. Plant J. 22:503-513.

López-Vidal, O., D. Camejo, F. Rivera-Cabrera, M. Königsberg, J.M. Villa-Hernández, J.A. Mendoza-Espinoza, and F.D. de LeónSánchez. 2016. Mitochondrial ascorbate-glutathione cycle and proteomic analysis of carbonylated proteins during tomato (Solanum lycopersicum) fruit ripening. Food Chem. 194:1064-1072.

Ma, N., H. Feng, X. Meng, D. Li, D. Yang, C. Wu, and Q. Meng. 2014. Overexpression of tomato SINAC1 transcription factor alters fruit pigmentation and softening. BMC Plant Biol. 14:351.

Martí, R., S. Roselló, and J. Cebolla-Cornejo. 2016. Tomato as a source of carotenoids and polyphenols targeted to cancer prevention. Cancers (Basel) 8:58.

Mène-Saffrané, L. and D. DellaPenna. 2010. Biosynthesis, regulation and functions of tocochromanols in plants. Plant Physiol. Biochem. 48:301-309.

Namitha, K.K., S.N. Archana, and P.S. Negi. 2011. Expression of carotenoid biosynthetic pathway genes and changes in carotenoids during ripening in tomato (Lycopersicon esculentum). Food Funct. 2:168-173.

Nour, V., I. Trandafir, and M.E. Ionica. 2010. HPLC organic acid analysis in different citrus juices under reversed phase conditions. Not. Bot. Horti Agrobot. Cluj-Napoca 38:44.

Özyürek, M., K. Güçlü, E. Tütem, K.S. Başkan, E. Erçağ, S.E. Celik, and R.A. Apak. 2011. Comprehensive review of CUPRAC methodology. Anal. Methods 3:2439-2453.

Perry, A., H. Rasmussen, and E.J. Johnson. 2009. Xanthophyll (lutein, zeaxanthin) content in fruits, vegetables and corn and egg products. J. Food Compos. Anal. 22:9-15.

Quadrana, L., J. Almeida, S.N. Otaiza, T. Duffy, J.V. Correa da Silva, F. de Godoy, R. Asís, L. Bermúdez, A.R. Fernie, F. Carrari, and M. Rossi. 2013. Transcriptional regulation of tocopherol biosynthesis in tomato. Plant Mol. Biol. 81:309-325.

Re, R., N. Pellegrini, A. Proteggente, A. Pannala, M. Yang, and C. Rice-Evans. 1999. Antioxidant activity applying an improved ABTS radical cation decolorization assay. Free Radic. Biol. Med. 26:12311237. 
Rodríguez, G.R., J.H. Pereira da Costa, G.R. Pratta, R. Zorzoli, and L.A. Picardi. 2013. Recursos genéticos y genómicos para mejorar la calidad del fruto en tomate. Agromensajes 35:30-36.

Stahl, W. and H. Sies. 2003. Antioxidant activity of carotenoids. Mol. Aspects Med. 24:345-351.

Steiner, A.A. 1961. A universal method for preparing nutrient solutions of a certain desired composition. Plant Soil 15:134-154.

Untergasser, A., H. Nijveen, X. Rao, T. Bisseling, R. Geurts, and J.A. Leunissen. 2007. Primer3Plus, an enhanced web interface to Primer3. Nucleic Acids Res. 35:W71-W74.

Villa-Hernández, J.M., T.D. Dinkova, R. Aguilar-Caballero, F. RiveraCabrera, E.S. De Jiménez, and L.J. Pérez-Flores. 2013. Regulation of ribosome biogenesis in maize embryonic axes during germination. Biochimie 95:1871-1879.

Viuda-Martos, M., E. Sánchez-Zapata, E. Sayas-Barberá, E. Sendra, E. Pérez-Álvarez, and J. Fernández-López. 2014. Tomato and tomato by products. Human health benefits of lycopene and its application to meat products: A review. Crit. Rev. Food Sci. Nutr. 54:1032-1049.

Wrolstad, R.E. 1993. Color and pigment analyses in fruit products. Oregon State Univ. Agr. Expt. Sta. Bul. No. 624.

Zanfini, A., G. Corbini, C. La Rosa, and E. Dreassi. 2010. Antioxidant activity of tomato lipophilic extracts and interactions between carotenoids and $\alpha$-tocopherol in synthetic mixtures. LWT-Food Sci. Technol. 43:67-72.

Zhang, Y., E. Butelli, R. De Stefano, H.J. Schoonbeek, A. Magusin, C. Pagiarani, N. Wellner, L. Hill, D. Orzaez, A. Granell, J. Jones, and C. Martin. 2013. Anthocyanins double the shelf life of tomatoes by delaying overripening and reducing susceptibility to gray mold. Curr. Biol. 23:1094-1100.

Zhu, M., G. Chen, S. Zhou, Y. Tu, Y. Wang, and T.Z. Dong. 2014. A new tomato NAC (NAM/ATAF1/2/CUC2) transcription factor, SINAC4, functions as a positive regulator of fruit ripening and carotenoid accumulation. Plant Cell Physiol. 55:119-135. 